\title{
Communal institutions for the management of rangeland resources and dairy production in Taleghan Valley, Northern Iran
}

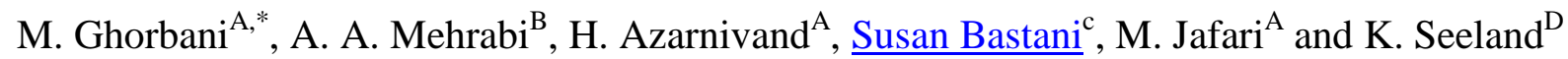

\footnotetext{
${ }^{A}$ Faculty of Natural Resources, University of Tehran, PO Box 31585 - 4314, Iran.

${ }^{\mathrm{B}}$ Department of Watershed Management, Science and Research Branch, Islamic Azad University, PO Box 31585 4314, Iran.

${ }^{\mathrm{C}}$ Faculty of Social Sciences and Economics, Alzahra University, Iran - 1993891176. DETHZ, Institute for Environmental Decisions - Group Society, Environment and Culture, Zürich 8092, Switzerland.
}

\begin{abstract}
Mutual help among pastoralists plays a key role in herding in rural Iran where pastoralists share a rich knowledge of dairy production. Nariyan village, located in the Taleghan region in Northern Iran, was chosen for this study on local traditions of the dairy production chain because it is still largely based on reciprocal sharing of labour and milk and local traditions of social cohesion. The results reveal that an elaborate network of communal institutions, based on seasonal cooperation, exists among pastoralists that regulate the use and management of milk and milk products. Different social roles, such as those of owners of herds of different sizes, herd manager and shepherds, are organised in a traditional co-operative institution, called Shirvâreh, a summer seasonal cooperative that strengthens social ties among the pastoralists and guarantees an efficient dairy production chain for subsistence and marketing. Precise data on milk-sharing reciprocity, such as are provided in this paper, seem to be rare for this geographical region if there are any at all, and this fills a gap in empirical rangeland science as it adds to the theory of traditional knowledge being a means to harmonise societal inequalities.
\end{abstract}

Keywords: cooperative livestock management, local collective action, milk exchange, mutual help, social cohesion. 